\title{
Ten-year Development Trends and Issues of the Chinese Government Guidance Fund from 2011 to 2020
}

\author{
Chunhui Zhang \\ Nanjing Normal University, Nanjing 210023, Jiangsu, China \\ Email: 1151220060@qq.com
}

\begin{abstract}
In the ten years from 2011 to 2020, the Chinese government guidance fund has experienced a development stage from steady development to rapid explosion and then gradually returning to rationality. At present, the number and scale of the establishment of government guidance funds have achieved steady development, the development of Northwestern China has accelerated, and the investment hotspot has gradually shifted from the Internet to the core technology field. However, there are still problems such as uneven regional development, insufficient social capital, and low utilization of some funds. It is recommended to start with the establishment of funds according to local conditions and relax geographical restrictions to improve management and promote the healthy and long-term development of government-guided funds. Keywords: government guidance fund, rational regression, equilibrium, utilization rate
\end{abstract}

\section{Introduction}

At present, China's economic development has entered a new normal, and the macro-economy has come to an important turning point in industrial upgrading and economic transformation. As an important tool for promoting enterprise development, making up for market failures, and transforming financial investment methods in this historical development stage, government guidance funds are playing an indispensable role. Since the establishment of China's first government guidance fund - Zhongguancun Venture Capital Guidance Fund in 2002, the government guidance fund has entered its 20th year in China. As of the end of 2020, the total number of Chinese government guidance funds has reached 1,741, with a total raised amount of 11,073,194 million yuan, showing an overall prosperous trend. For a long time, the government guidance fund has played a role in exerting the leverage amplification effect of fiscal funds and increasing the supply of venture capital capital, escorting China's economic development. This article summarizes the development trend and existing problems of government guidance funds in the past decade from 2011 to 2020, and puts forward some practical and feasible suggestions, hoping to provide some references for the standardized development of funds.

\section{Ten-year development trend of government guidance funds from 2011 to 2020}

\subsection{The growth of government guidance funds slows down and gradually returns to rationality}

In 2005, the ten ministries and commissions of the central government issued "the Interim Measures for the Management of Venture Capital Enterprises", which clearly stipulated that the state and local governments can establish venture capital guidance funds to guide private capital into the venture capital industry. Since then, the Chinese government's guidance fund has gradually developed under the promotion of policies, injecting new vitality into the field of venture capital. The specific establishment during the ten years from 2011 to 2020 is shown in Figure 1 and Figure 2.

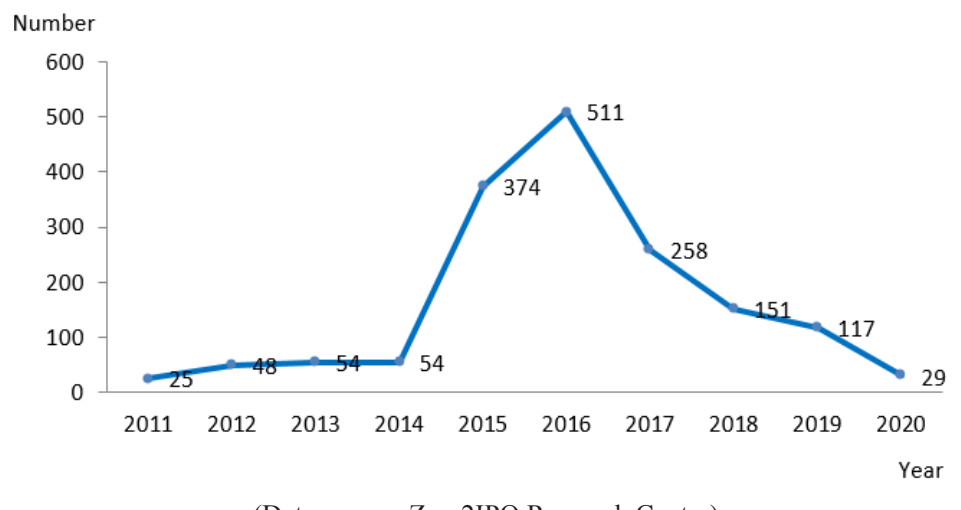

Figure 1. 2011-2020 trends in the establishment of government guidance funds 
Under the continuous promotion of the "innovation and entrepreneurship" policy, the Chinese government guidance fund, as an important force in promoting innovation and promoting entrepreneurship, ushered in an explosive period from 2015 to 2017, and the number and scale of establishments showed a spurt of growth. In 2015, there were 374 newly established funds, which was 6.93 times the number established in 2014. The scale of raised funds reached 432.9 billion, reaching the 100 billion level for the first time, which was 7.02 times the scale raised in 2014, and there were dozens of tens of billions of the government guidance fund was established in that year. In 2016, the number of newly established guiding funds reached 511, with a raised amount of 540.2 billion yuan, which is the year with the largest number of newly established government guidance funds and the largest raised scale so far. Although the number of newly established funds in 2017 was small, accounting for only about half of 2016, the amount raised remained at more than 400 billion yuan, and the average fundraising scale of each fund increased by 58.2\% compared with 2016 .

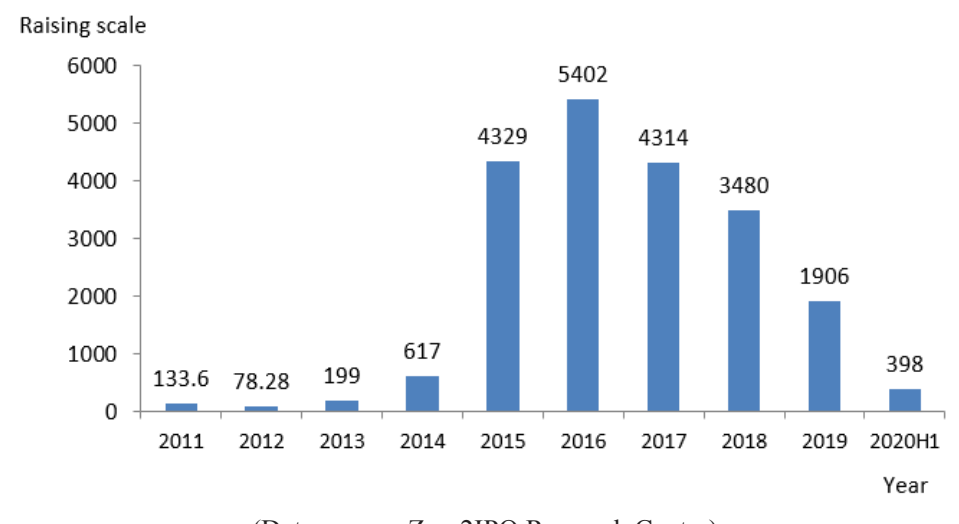

(Data source: Zero2IPO Research Center)

Figure 2. 2011-2020H1 government guidance fund raising scale trend chart

In 2018, the global economic growth momentum has slowed down, the international financial market has diverged, and the overall financial environment has tightened. Domestically, credit has been shrinking since 2018, and the 20-year long credit cycle has come to an end. The new asset management rules mean that the country's supervision of the financial industry has been continuously strengthened. Affected by the above factors, the overall activity of the domestic venture capital market has declined, and the number and scale of government guidance funds have also declined. In 2018, the number of established funds dropped by $41.5 \%$, and the scale of fundraising dropped by $19.3 \%$.In 2019 , with the reform of benchmark interest rates and a new round of interest rate cuts, financial market volatility has intensified, coupled with the intensification of trade war between the US and China, the domestic venture capital market has further shrunk. 117 new guidance funds were established throughout the year, a decrease of $22.5 \%$ compared to 2018 , and the scale of fundraising declined even more, which was $45.2 \%$.In 2020, the new crown pneumonia epidemic has caused great damage to the domestic economy, and the trend of global spread has made the venture capital environment worse. Under the impact of the epidemic, only 29 guidance funds have been established throughout the year.

In summary, during the decade from 2011 to 2020, after the government guidance fund has experienced steady growth and rapid development, the current growth rate has slowed down and the development trend has begun to become stable. This trend is mainly caused by the reduction of government investment, the limited capital contribution of banks due to financial supervision, and the incomplete use of existing government guidance funds. It also shows that the current venture capital market focuses on risk management and investment is gradually returning to rationality.

\subsection{The direction of investment has changed significantly, focusing on core technology areas}

Based on the statistical data of market research institutions such as Zero2IPO Research Center and ChinaVenture Investment Consulting Research Institute and other public data, the key investment areas of government guidance funds over the years have been sorted out, as shown in Table 1 .

Table 1. Key investment areas of government guidance funds over the years

\begin{tabular}{cc}
\hline Year & Key investment areas \\
\hline 2015 & TMT, healthcare, consumer goods and services, finance \\
2016 & Healthcare, artificial intelligence, TMT, Internet of Things, big data \\
\hline
\end{tabular}




\begin{tabular}{|c|c|}
\hline Year & Key investment areas \\
\hline $2017-2018$ & $\begin{array}{c}\text { Electronic and optoelectronic equipment, semiconductors, machinery manufacturing, telecommunications } \\
\text { and value-added services }\end{array}$ \\
\hline 2019 & Environmental protection public utilities, materials, energy and minerals, healthcare, new retail \\
\hline 2020 & $\begin{array}{l}\text { Semiconductor, optoelectronics and optomechanical integration, computer communications, biotechnology, } \\
\text { vaccine research and development }\end{array}$ \\
\hline
\end{tabular}

From the perspective of key investment areas, the research and development of core technology fields such as semiconductors, optoelectronics and optomechanical integration, communications, and high-end production equipment such as machinery manufacturing have attracted more and more attention from government guidance funds. Medical health is the direction that the government guidance fund always pays attention to, and a large proportion of investment flows into this field almost every year. Affected by the new crown pneumonia epidemic, medical investment in 2020 will be more detailed, biased towards the direction of biotechnology and vaccine research and development.

In 2015 and 2016, cloud computing and mobile Internet technology developed rapidly, and the network penetration rate increased rapidly. Therefore, the Internet field has been favored in the past two years. TMT became the largest investment inflow direction of the guiding fund in 2015, and it is to incorporate artificial intelligence, TMT, Internet of Things, and big data into the key areas of investment in 2016. But in recent years, the investment enthusiasm in the Internet direction has dropped significantly. This trend reflects that the government guidance fund pays more attention to overcoming the core technical difficulties that can gain a competitive advantage in the future technological competition, hoping to guide the solution of the current problems facing the country through capital injection, and minimize the potential risk of "stuck neck". Weaken the threat to the country's development from similar events like the trade war between the US and China.

\subsection{The speed of development of government guidance funds in the Northwest region has accelerated}

Since the establishment of the government guidance fund, the Northeast, Southwest and Northwest regions have been in a relatively weak position in terms of quantity and scale, and the gap between them is relatively large. However, in recent years, the growth rate of government guidance funds in the northwest region has increased significantly, while other regions have shown a trend of steady growth. Figure 3 shows the growth rate of the scale of government guidance funds in various regions from 2017 to 2019.

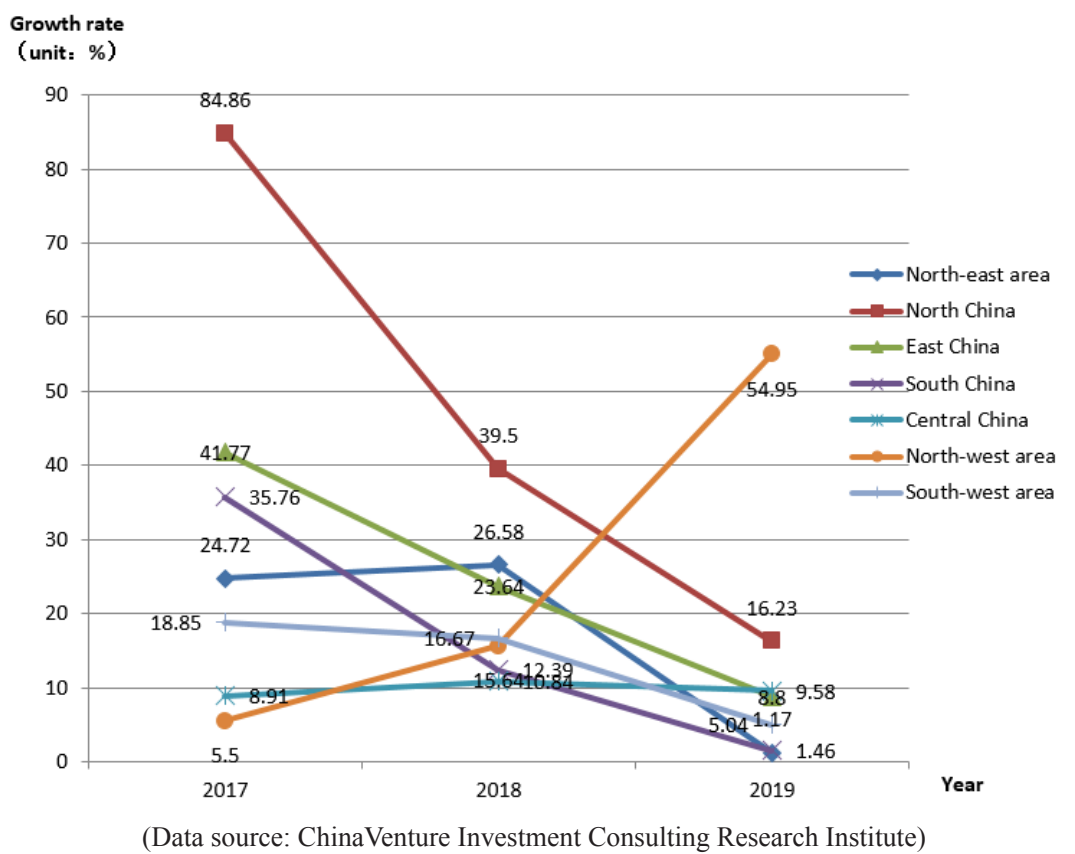

Figure 3. The growth rate of the scale of government guidance funds in various regions from 2017 to 2019

It can be seen from Figure 3 that the annual growth rate in Central China has remained flat, with a steady growth rate of 9\%-10\% per year. The growth rates of East China, South China, Central China and Southwest China have been declining year by year, and the growth rate of South China in 2019 was only $1.46 \%$. The growth rate of the Northeast 
region increased in 2018, but the growth rate in 2019 fell to $1.17 \%$, which is the slowest growth region in the country. The growth rate in North China has dropped sharply, from $84.86 \%$ in 2017 to $16.23 \%$ in 2019 .

The development speed of the government guidance fund in the Northwest Region has accelerated significantly, from $5.5 \%$ in 2017 to $54.95 \%$ in 2019 , an increase of nearly 9 times. This also shows the country's determination to promote the high-quality development of the northwest region and do a good job in the development of the western region.

\section{The remaining problems of government guidance funds}

\subsection{Uneven development in various regions}

Since its establishment, government guidance funds have had a serious imbalance in the geographical distribution. The government guidance funds in East China steadily occupy the first place in terms of quantity and scale, far exceeding other regions. In terms of quantity, East China occupies almost half of the country, while Northeast China accounts for only $4 \%$, and Northwest China accounts for $5 \%$. There is a large gap between the two regions and other regions. In terms of scale, East China occupies 34\%, which is also at the top of the list, while the smallest Northeast region accounts for only $2 \%$, and the Northwest and Southwest regions are also less than $10 \%$.It can be seen from this that the guiding funds in the coastal area are in a sufficient state and can play a full "boosting" role to help scientific and technological projects connect with the capital market and realize the transformation of results. There is still room for improvement in the "leading" role of government guidance funds in the northeast and western regions. At present, the growth rate of the northwest region is beginning to rise, but the northeast and southwest regions are still in a situation of weak foundation and weak growth.

\subsection{Limited ability to leverage social capital}

One of the original intentions of the establishment of the government guidance fund is to guide social capital and promote the formation of a mechanism for the accumulation of venture capital. The development of China's local LP market is still in its infancy, and according to data released by the China Association of Funds Industry, government guidance funds are the third largest type of LP, accounting for $11.1 \%$. This shows that, on the one hand, government guidance funds have become one of the main sources of venture capital. On the other hand, the endorsement of government credit will attract social capital and foreign capital into the field of venture capital.

But at present, the government guidance fund's leverage on social capital is not ideal. According to "The State Audit Office's Audit Work Report on the 2016 Central Budget Implementation and Other Financial Revenues and Expenditures" issued by the National Audit Office in June 2017, a total of 235 funds in 16 provinces were spot-checked, and the introduction of social capital accounted for only $15 \%$ of the actual funds in place. In another random inspection of 149 government and social capital cooperative toll road projects in 20 provinces, 91 failed or terminated, accounting for as much as $61 \%$.

2020 is the last year of the transitional period of the "new asset management regulations". Starting from 2021, the strengthening of supervision will intensify the high pressure in the investment market. It is foreseeable that with the attractiveness of existing government guidance funds to social capital, the difficulty of fundraising and operation will be greatly increased.

\subsection{There is still room for improvement in utilization}

According to the annual audit report issued by the State Council, the unutilized situation of government guidance funds is summarized in Table 2. It can be seen that the utilization rate of some government guidance funds is still relatively low, so that the guiding role of the funds has been greatly weakened, which is contrary to its purpose.

Table 2. Utilization rate of government guidance funds

\begin{tabular}{ccc}
\hline Release time & Report name & Specific situation \\
\hline June 28, 2015 & $\begin{array}{c}\text { The State Council's Audit Work Report on the } \\
\text { Implementation of the Central Budget and Other } \\
\text { Financial Revenues and Expenditures in 2014 }\end{array}$ & $\begin{array}{c}\text { As of the end of 2014, 39.756 billion yuan (84\%) of } \\
\text { venture capital funds raised in 14 provinces since 2009 } \\
\text { were unused, and 4 provinces have never spent them. }\end{array}$ \\
June 20, 2018 & $\begin{array}{c}\text { The State Council's Audit Work Report on the } \\
\text { Implementation of the Central Budget and Other } \\
\text { Financial Revenues and Expenditures in 2017 }\end{array}$ & $\begin{array}{c}\text { Among the 36 venture capital guiding Funds in 11 } \\
\text { provinces, 6 of them have never invested abroad, } \\
\text { involving 780 million yuan of funds. }\end{array}$ \\
June 18, 2020 & $\begin{array}{c}\text { The State Council's Audit Work Report on the } \\
\text { Implementation of the Central Budget and Other } \\
\text { Financial Revenues and Expenditures in 2019 }\end{array}$ & $\begin{array}{c}\text { Of the 127.274 billion yuan actually put in place by the } \\
\text { 47 government investment funds in 8 provinces, 41.174 } \\
\text { billion yuan (32.4\%) did not invest. }\end{array}$ \\
\hline
\end{tabular}




\section{Countermeasures and suggestions}

\subsection{Adjust measures to local conditions and set up characteristic government guidance funds for the central and western regions and northeastern regions}

There are many enterprises in the eastern region and the industrial chain is very complete. The available investment targets involve various fields. Therefore, most funds are comprehensive funds. However, the central and western regions are restricted by factors such as economy, geography, and talent, and have relatively few industries. Therefore, it is possible to set up a characteristic and refined government guidance fund suitable for local development in accordance with local conditions. For example, according to the "Catalogue of Encouraged Industries in the Western Region" formulated by the National Development and Reform Commission, the government-guided fund of the Tibet Autonomous Region can establish sub-funds such as combustible ice technology and solar photovoltaic power generation technology in the high-cold tundra, and the Xinjiang Uygur Autonomous Region can set up uranium mining and smelting. Funds for equipment research and development, bentonite mining technology, etc. This can not only reduce the problem of the lack of investment options for comprehensive funds in the central and western regions and the northeast, but also lead the social capital to pay attention to outstanding projects in the central and western regions, which is conducive to the innovation and development of the central and western regions, employment, and corporate financing. Talent cultivation will eventually promote these areas to catch up with the pace of development.

\subsection{Relaxation of geographical restrictions on the selection of investment targets}

Prior to 2016, government investment funds were extremely regional, and their investment objects were limited to the local area, that is, municipal funds only invested in enterprises in the city where they were located, while provincial funds only invested in enterprises in the province, and there were strict regulations on "local enterprises". In 2016, some regions began to realize that this kind of geographical restriction greatly reduced the selectivity, which was not conducive to long-term development, and introduced new management methods. For example, the Zhejiang Provincial Innovation and Powerful Industrial Fund has issued new regulations: "For sub-funds whose shareholding ratio of innovation funds is less than (including) 20\%, the proportion of funds invested in enterprises in the province can be reduced as appropriate."

Up to now, there are still a small number of funds that have relaxed restrictions. Other funds can also learn from Zhejiang Province's practice and appropriately relax geographical restrictions on the selection of investment targets in order to seek the long-term development of funds.

\section{Conclusion}

The purpose and significance of the government's establishment of the guidance fund is to further leverage the leverage of financial funds, solve financing problems for enterprises in the seed stage and start-up stage, gradually overcome the difficulties in technology and equipment research and development, guide and drive the development of industries and regional economies, and ultimately enhance the overall national strength. In particular, China is currently in an important transitional period of industrial upgrading and economic transformation, and it is suffering from the impact of the epidemic, and it urgently needs to boost the economy. The assistance of government guidance funds is especially important. Next, we can gradually improve the management methods of government guidance funds by accelerating the growth rate of underdeveloped regions and alleviating geographical restrictions, so as to lay a solid foundation for longterm development.

\section{References}

[1] Yue Du, Xiaoni Ying. Government Venture Capital Guidance Fund: Rational Return after Explosive Growth. Macroeconomic Management. 2018; (05): 35-39.

[2] Shanmin Li, Xingyun Liang, Dazhong Wang. The guiding effect and mechanism of the Chinese government guidance fund. Southern Economy. 2020; (08):1-16.

[3] Xiaolan Deng, Changpeng Sun. The mechanism of corporate innovation, industrial upgrading and government guidance funds. Journal of Shanxi University of Finance and Economics. 2019; 41(05): 54-67.

[4] Zero2IPO Research Center. Research Report on the Development of Jingjin Guided by the Chinese Government in 2010. 2019. 
[5] ChinaVenture Investment Consulting Research Institute. Special report of the Chinese Government Guidance Fund. 2020.

[6] Xiaofeng Cui. (2019) Research on Performance Evaluation of Xiamen Government Guidance Fund. Xiamen University, Xiamen.

[7] Kangheng Wang. (2019) Research on the Development of China Industrial Investment Funds. Huazhong Normal University, Wuhan. 